\title{
Arbor
}

\section{El nuevo paradigma estratégico}

\author{
Jesús Rafael Argumosa Pila
}

Arbor CLXV, 651 (Marzo 2000), 529-564 pp.

Quién se prepara con prudencia para enfrentarse al enemigo que aún no existe obtendrá la victoria. Poner como pretexto su rusticidad y no prever es el más grande de los crímenes; estar presto fuera de toda contingencia es la mejor de las virtudes.

Esta es una de las cinco condiciones para lograr la victoria.

Sun Tzu. Siglo VI a. de C.

\section{Introducción}

En los últimos años del final del segundo milenio ha comenzado el proceso de diseño de un nuevo orden mundial en el que se está estableciendo una moderna doctrina de seguridad así como un emergente modelo de estrategia global que responda a las transformaciones de todo tipo que se están sucediendo, de forma acelerada, en estos momentos y en el previsible próximo futuro, en todo el planeta.

No cabe duda que el diseño de este nuevo orden, si realmente tiene credibilidad, tiene que disponer fundamentalmente de una estructura política, económica y de seguridad que sea capaz de hacer frente a los retos y riesgos que puedan poner en cuestión los principios y valores universales, aún por definir, en los que se debe sustentar la comunidad internacional.

Por otra parte, la reciente crisis de Kosovo ha conmocionado al pueblo europeo, en particular, y a la sociedad mundial, de forma general, cambiando sustancialmente el orden de los valores que se había establecido al finalizar la Segunda Guerra Mundial. El derecho de intangibilidad de las fronteras de los estados ha sido puesto por debajo del derecho de injerencia por razones humanitarias. Será necesario 
en el cercano futuro construir una nueva legalidad que regule con solidez, credibilidad y coherencia el citado derecho de injerencia.

Lógicamente, la aplicación de este derecho de injerencia por razones humanitarias debe extenderse a todos los lugares y pueblos de la tierra que sufran estas situaciones. No es razonable ni admisible su utilización únicamente en aquellos territorios donde se encuentran intereses de las grandes potencias, de ciertas organizaciones internacionales o de potencias regionales mientras que no se emplean en otros escenarios $o$ en sociedades que padecen los mismos o mayores sufrimientos.

También es cierto que la guerra de Kosovo no se ha hecho ni por el petróleo ni por otro tipo de intereses políticos o geoestratégicos, sino más bien por principios. En este sentido, ha sido muy diferente a la Guerra del Golfo, el otro conflicto importante que ha ocurrido en la post guerra fría. Los dos han ocasionado profundas y graves repercusiones en la estabilidad mundial. Parece que ambos tipos de conflictos pueden ocurrir en esta nueva era que nos depara el inicio del próximo siglo.

Por otro lado, están apareciendo nuevas dimensiones en la situación internacional que apenas se percibían hace una década. La dimensión social frente a la dimensión tecnológica y el mundo del conocimiento junto con el de la inteligencia, constituyen aspectos importantes a tener en cuenta en el inmediato futuro. Asimismo, nuevos conceptos como los del tiempo real o del dominio del espacio están introduciendo métodos de razonamiento y de tomas de decisión insospechados.

\section{Marco conceptual}

A grandes rasgos, desde sus orígenes hasta la II Guerra Mundial, la estrategia se ha movido siempre en el contexto de la guerra, sin radicales cambios o transformaciones, apoyándose fundamentalmente en las operaciones militares y, ya desde Clausewitz, encajada perfectamente en el espectro político. Inicialmente el objetivo consistía en alcanzar la victoria hasta que el pensador prusiano le añadió un objetivo más ambicioso y real que era la finalidad política.

Sin embargo, desde la II Guerra Mundial, han aparecido tres fenómenos totalmente distintos. En primer lugar, se ha asistido a la evolución progresiva de los tratadistas militares clásicos, principalmente el británico Liddell Hart, el francés Beaufre y el norteamericano Collins, con análisis rigurosos y racionales del campo estratégico tradicional aunque ya incluyendo visiones más extensas del concepto. 


\section{El nuevo paradigma estratégico}

En segundo lugar, el nacimiento del nuevo término de estudios estratégicos en el que sus partidarios tales como Bernard Brodie, Pierre Gallois, Henry Kissinger, Maxwell Taylor o Barry Buzan introdujeron factores y elementos totalmente nuevos en el escenario estratégico, dando a la estrategia, ciertamente, una concepción y un contenido muy amplios.

Por último, la aparición en los últimos años del concepto de política de seguridad, el surgimiento de nuevos actores estratégicos y modernos factores a tener en cuenta y la extensión en el tiempo de la aplicación de la estrategia, introduce una nueva situación en la que resulta necesario abrir un periodo de reflexión con objeto de delimitar y definir claramente los campos y los conceptos de la estrategia. El francés Lucien Poirier y el británico Neville Brown han dado los primeros pasos en este nuevo planteamiento.

Los tres movimientos mencionados tienen un denominador común: por un lado, el término guerra ha ido desapareciendo y se sustituye por nuevos conceptos tales como conflictos, crisis, tensiones... etc.; por otro, la estrategia no sólo ha adquirido un campo de acción muy extenso, integrando un gran número de aspectos, sino que además su enfoque tiende a ser planetario, de tal forma que, al igual que la seguridad, todo hecho, acción u operación que se realice en cualquier parte del mundo, tiene repercusión o incidencia en el campo estratégico.

En otra línea de análisis, hay que diferenciar el modelo teórico del modelo práctico. Una cosa es tratar los tres niveles teóricos de la estrategia, en el campo de la seguridad, de la defensa y de lo militar y otra es aplicarla dentro de la estructura estatal de cada país $\mathrm{u}$ organización como sujeto o actor estratégico. Cuando en este trabajo se habla de la estrategia de seguridad se está siguiendo la interpretación dada por Liddell Hart y Collins a la Gran Estrategia o por Beaufre a la Estrategia Total, aunque con mayor extensión, de acuerdo con las tendencias existentes en los últimos años, antes mencionadas.

Así, en el modelo que se practica tanto en la OTAN como en los Estados Unidos, la estrategia está fundamentalmente basada en el horizonte de la seguridad y en el horizonte militar. El nivel estratégico de la defensa, se limita a dar directrices, instrucciones u orientaciones al nivel militar dedicando su esfuerzo a la aportación que deben dar otros departamentos a la defensa. Ello no es óbice para que la estrategia de defensa integre, controle y supervise, cuantas veces lo crea oportuno, el desarrollo de la estrategia militar. 
En el Reino Unido, sin embargo, la estrategia se sustenta principalmente en el nivel de la estrategia de la defensa, donde se recogen las disposiciones que derivan del nivel de la estrategia de la seguridad e integra las correspondientes al nivel de la estrategia militar. En este modelo están estrechamente enlazados y concentrados los tres niveles de la estrategia.

Otro tercer modelo, lo podemos encontrar en la mayor parte de los países de Europa Occidental, donde se contempla un Libro Blanco que incluye los conceptos de política de seguridad, de política de defensa, y de política militar así como los diferentes niveles de la estrategia, expuestos más arriba, pero sin una separación clara y delimitada de lo que incluye cada una de las acepciones citadas.

En este momento se va a tratar fundamentalmente el nivel de la estrategia de seguridad, en especial en el horizonte planetario, intentando definir lo más aproximado posible cuales son y en que estructura se hallan los principales componentes del moderno paradigma estratégico que debe hacer frente a los riesgos y desafíos del inicio del nuevo siglo.

Para ello, el marco conceptual estratégico que se va utilizar realiza una síntesis del entorno de seguridad actual y su posible evolución, fija los objetivos de la comunidad internacional, detalla los criterios básicos y las líneas de acción para alcanzarlos, así como los diferentes ámbitos de actuación y las características de los medios que se requieren para ejecutarla. Todo lo anterior se desarrolla por unos actores estratégicos dentro de las reglas del orden mundial establecido.

\section{Orden mundial}

Con un alto grado de acierto, el orden mundial de los inicios del próximo siglo estará basado fundamentalmente en la coexistencia de las grandes potencias, las organizaciones internacionales y las áreas geoeconómicas sobre las que actuarán permanentemente las civilizaciones. Tendrá un carácter complejo y en él existirán múltiples zonas de solape entre los diferentes actores y entidades citados que darán una continuidad al constante flujo de ideas, pensamientos y culturas de la aldea global de la comunidad internacional.

Se le denominará un orden mundial sin fronteras. Será un orden internacional continuo, sin fronteras definidas pero fuertemente interrelacionado, interconexionado y sistematizado, es decir, integrado. 


\section{Ell nuevo paradigma estratégico}

Muy probablemente, en los primeros años del siglo XXI, las grandes potencias como Estados Unidos, China, la Unión Europea, Rusia, Japón e India tendrán el mayor peso en el establecimiento del mencionado orden planetario para dar paso de forma paulatina y progresiva al protagonismo de las organizaciones internacionales, de las que una primera aproximación se representan en el mapa $\mathrm{n}^{0} 1$.

El sentimient" de pertenencia a la aldoa global serâ mảs acusado ya que los valore! comunes y universales de las diferentes civilizaciones se habrán extemılldo a gran parte de la sociedad internacional. Esta situación puede llar lugar a compartir vivencias, principios, pensamientos y expericicias que provocarán un mayor acercamiento y comprensión entre lo: pueblos.

Sin embargo, todavía existirán amplios segmentos de la comunidad mundial sometidos a condiciones verdaderamente denigrantes e intolerables, especialnente en aquellos vacíos geopolíticos donde las grandes potencias o las or granizaciones internacionales tienen más o menos dificultades para actuar. Regiones como Iberoamérica, Africa Subsahariana, Oriente Medio, Asia Central y Sudeste de Asia posiblemente se hallarán en esta situación.

La doctrina de seguridad de los primeros años del próximo siglo se caracterizará fundamentalmente por la promoción y defensa de los derechos humanos y los valores democráticos junto al respeto a las minorías y al gobierno de la ley. Quedan ya obsoletos los principios de la guerra fría de no injerencia en asuntos internos, integridad e intangibilidad de fronteras.

La situación estratégica mundial, caracterizada por la gran velocidad a la que se desarrollan los acontecimientos y la consiguiente inexistencia de directrices claras para un futuro a medio plazo, presenta indicadores de encontrarse en puertas de una nueva era.

En líneas generales, el incipiente orden planetario considera un conjunto de actores estratégicos con diferentes grados de poder e influencia pero cuyas decisiones tienen una gran importancia, unas veces a escala regional y otras en el ámbito planetario.

El más alto nivel corresponde a las grandes potencias en el sentido clásico del término, es decir, poderes capaces de protagonismo a nivel planetario. Hoy en día, como ya se ha apuntado, se consideran a los Estados Unidos, la Unión Europea, China, Rusia, Japón e India como tales. Debemos hacer la salvedad que entre ellas sobresale claramente Estados Unidos conno única que verdaderamente reúne todos los requisitos. Casi con loda probabilidad, esta afirmación respecto a los Estados Unidos seguirá teniendo vigencia dentro de unas décadas, 
pero en la proyección de su poder sobre ciertas regiones, las diferencias con los actores en presencia se acortarán hasta el punto que sea mucho más problemático para ella ejercer su poder en estas zonas que en los momentos actuales. Ello hará que presumiblemente los Estados Unidos acentúen la característica fundamental que en los últimos años han tenido sus intervenciones militares: la selectividad.

Un segundo orden de poder se halla en otros países llamados, sin duda, a ejercer un polo de atracción a nivel regional. Son las potencias regionales. Entre ellas, se encuentran una posible Corea unificada, Australia, Indonesia, Irán, África del Sur, Nigeria, Brasil y Argentina.

Para finalizar con el análisis de las potencias, no debemos olvidar el poder militar que en la actualidad, y previsiblemente en mayor medida en un futuro próximo, desarrollarán estados que hasta hace pocos años no contaban en la escena internacional, basándose en la consecución de un instrumento militar de bajo coste e incluso tecnología poco avanzada, pasando por armas de destrucción masiva o NBQ. Este tipo de actuación, normalmente adoptado por países de nivel económico no elevado y de organización socio-política de corte autoritario, podría ser de gran rentabilidad mediante la aplicación de golpes aislados, su utilización masiva y más dilatada en el tiempo o la simple amenaza de su uso. Se les llama estados felones para indicar que no siguen las reglas establecidas por la comunidad mundial.

Pero al mismo tiempo, junto a la "renacionalización" de poderes que se está produciendo a nivel de todo el planeta, convive la idea de la integración que, lógicamente, según los pasos que hoy se pueden dar, tiene dimensión regional o internacional. Así, actualmente comparten espacio toda una serie de intentos más o menos consolidados de organizaciones internacionales de tipo político, económico o de seguridad de los múltiples actores. Estos intentos varían en intensidad de voluntades, de eficacia y en la amplitud del camino recorrido. Desde la ONU y la OTAN hasta el FMI y la APEC, tenemos todo tipo de ejemplos en el sentido apuntado anteriormente.

No obstante el importantísimo papel que tienen los estados como sujetos políticos actuales en el concierto internacional, es necesario apuntar la existencia de fuerzas internas a ellos que en muchos casos actúan como elementos disgregadores. Nos referimos a los nacionalismos. En este sentido, gran número de estados se mueven entre tendencias aglatínadoras o disgregadoras respecto a su esfera interna, en paralelo con sus intentos de reafirmación a nivel regional o mundial y de sucesivos pasos de integración. Todas estas características, algunas 


\section{El nuevo paradigma estratégico}

de ellas de naturaleza contraria a las otras, pueden darse simultáneamente, de forma que en determinados momentos es difícil determinar cual predomina.

Otra de las características de la época presente es la extraordinaria importancia que están adquiriendo otras iniciativas ajenas al contexto estatal, como puede ser la gran variedad de estructuras que responden a la voluntad de grupos y organizaciones de carácter privado, de alcance nacional o internacional, las denominadas Organizaciones No Gubernamentales $(\mathrm{ONG}, \mathrm{s})$ que pujan por convertirse en actores estratégicos reconocidos de la escena mundial. Su incidencia actual en la Estrategia Global es innegable e irá en aumento con toda seguridad.

Una última gradación de poder y en el mismo terreno de iniciativas ajenas a la voluntad de los estados, pero en esta ocasión con alcance normalmente nacional, lo conforma la actuación de organizaciones que suelen representar actitudes no siempre coincidentes con las de sus gobiernos, estableciendo lo que ha venido en denominarse Organizaciones Paramilitares. Este hecho, de gran importancia en algunos países, presupone la irrupción sobre el contexto estratégico a nivel interno de aquellos, de nuevos actores a tener en cuenta, sobre todo a la hora de los acuerdos de paz, del inicio de conflictos armados o de garantizar la seguridad y estabilidad en el territorio nacional.

En este ambiente donde el número de iniciativas a todos los niveles se multiplica de forma inimaginable hace unos años, otras fuerzas de distinta naturaleza actúan incidiendo sobre los poderes políticos de forma que llegan realmente a modular el entorno en que éstos deben actuar, exigiendo el análisis de la situación que se contemple mucho más que las relaciones entre estados. Es el caso de la gran importancia que ha adquirido el poder de la opinión pública, una de las características fundamentales que nos ha aportado el siglo que termina. Esta circunstancia, muy unida al poder de los medios de comunicación, se produce principalmente en los países con regímenes democráticos, estando mucho más diluida en los autoritarios. Debido a esta consideración, no se pueden afirmar, por ahora, que sea un fenómeno universal.

Otro factor que abunda en la línea ya apuntada del denominado golpe aislado es el del terrorismo internacional, promovido tanto por ciertos estados que obtienen así una forma económica de actuación, como organizaciones fuera de los ámbitos estatales cuya actividad puede poner en jaque a los gobiernos, representando para ellos uno de los quebraderos de cabeza más importantes de los próximos años.

En este contexto tan variado, los tres grandes motores que tienen actualmente una influencia decisiva en el mundo de las relaciones 
internacionales y en la configuración del nuevio orden planetario son las grandes potencias, las organizaciones internacionales de tipo político, económico y de seguridad, y las tres áreas geoeconómicas más desarrolladas del mundo, pilotadas por los EEUU, Europa y Japón.

Sobre todo el panorama anteriormente expuesto está actuando permanentemente el peso de las civilizaciones. Aunque éstas no son sustancialmente entidades políticas, a los efectos de este ensayo y en base a que reúnen un fuerte componente tradicional, histórico, religioso y cultural, constituyen unos actores que influyen poderosamente en la actuación y funcionamiento de los protagonistas más relevantes del orden mundial.

Ante este entramado de relaciones y actores estratégicos internacionales tan complejo, la Organización de Naciones Unidas trata de consolidar el marco que establece su Carta, siendo hoy día la legitimidad del denominado derecho de injerencia, apuntado más arriba, uno de sus caballos de batalla principales. Es indudable que en los últimos años, Naciones Unidas ha retomado el interés por ejercer su acción a través de los medios militares cuando sea necesario, para lo que puede valerse de Organizaciones ya establecidas como la OTAN o de otras organizadas «ad hoc». En todo caso, la legitimidad mundial normalmente pasa en este momento por las Resoluciones del Consejo de Seguridad, y así debiera seguir siendo en el futuro.

\section{Entorno de seguridad}

La globalización, como proceso de aceleración económica, tecnológica y cultural, significa que, con independencia de la integración política que está produciendo, las naciones cada vez más frecuentemente están afectadas por acontecimientos que suceden más allá de sus fronteras $\mathrm{y}$ ante los cuales tienen escasas posibilidades de control o de influencia.

Simultáneamente existe otro proceso de fragmentación que corre en sentido contrario al anterior, cuyo «pistoletazo de salida» fue dado por el desmembramiento de la Unión Soviética y Yugoslavia al finalizar el período de la "guerra fría». Con este paso se rompió el principio de «integridad territorial» que había imperado desde el final de la II Guerra Mundial.

La multiplicación de los estados continúa y así lo hará en los primeros años del próximo milenio. El protagonismo de éstos no se ha reforzado sino más bien se han revelado sus limites. Los nacionalismos existentes son cada vez más fuertes especialmente en los países más débiles. 


\section{El nuevo paradigma estratégico}

Dichos nacionalismos son defensivos en naturaleza y reflejan una falta de seguridad en si mismos en contraposición con los que existieron en las poderosas naciones del comienzo del siglo XX. El nacionalismo tiene mucha fuerza y las naciones-estado encuentran cada vez más difícil consolidar sus instituciones.

Los estados han perdido su monopolio en las relaciones internacionales y ahora pueden competir, y pueden ser sustituidos de hecho, por entidades multinacionales tales como corporaciones transnacionales, instituciones financieras, medios de comunicación y ONGs. El rol del estado ha cambiado, y ya el sistema internacional no puede ser descrito durante más tiempo simplemente como relaciones entre estados. A la estructura interestatal mundial tradicional es necesario superponerla otra con una multitud de actores y de relaciones variadas que da un carácter de complejidad a las relaciones internacionales. La globalización es un proceso que ha cambiado no solamente el contexto externo en el que operan los estados sino también la propia, naturaleza de los mismos y de las comunidades políticas.

Ell entorno actual y el que se espera para un futuro próximo se caracteriza fundamentalmente por la complejidad, la inestabilidad y la incertidumbre. En el campo de las estructuras y organizaciones políticas, económicas y de seguridad del escenario internacional, se siguen produciendo importantes y continuas mutaciones. En términos reales, antes de que se acabe la implantación del diseño de una estructura u organización es necesario hacer alguna modificación. Esto significa que cualquier modelo que se ponga en práctica en estos campos debe de tener como una de sus características principales la flexibilidad y capacidad de anticipación suficientes para adecuarse a los continuos cambios de ritmo de los nuevos tiempos.

El alcance de los medios de comunicación social, motivado por el avance de las nuevas tecnologías, ha propiciado una mayor sensibilización de la opinión pública sobre los conflictos internacionales y sus consecuencias sociales, lo que condiciona la toma de decisiones y el empleo de determinados medios incluidos los medios militares.

\section{Riesgos y oportunidades}

En la era de la globalización del conocimiento, de los mercados, de la tecnología y de las comunicaciones, existe una gran interdependencia en todos los órdenes no solamente de unos países respecto a 
otros sino también dicha interdependencia se manifiesta entre organizaciones supranacionales.

La simple defensa del territorio ya no es sinónimo de seguridad. La comunidad internacional se enfrenta a unos riesgos e inestabilidades complejos, que afectan a la seguridad, a la prosperidad y al bienestar de los ciudadanos.

Estos no se contrarrestan únicamente defendiendo las fronteras del territorio nacional, sino que es necesario también extender la concepción de la seguridad de modo que se esté en disposición de impedir que los intereses y valores universales se vean afectados en cualquier lugar del mundo, utilizando para ello medidas de índole política, cultural, diplomático, económico o militar, de entidad proporcionada.

Entre los riesgos más importantes a considerar se destácan los problemas económicos, sociales y políticos como productores de inestabilidad; la aparición de desequilibrios estratégicos; el resurgir de nacionalismos de diferentes tipos; la secesión e irredentismo; la lucha por la hegemonía regional; las disputas territoriales; la proliferación de armamento de destrucción masiva; la interrupción del flujo de recursos vitales o de información; los intentos fallidos de reformas; los extremismos religiosos, acciones del terrorismo internacional y sabotajes; el narcotráfico y la aparición del crimen organizado; la inmigración no regulada de refugiados procedentes de países no desarrollados y las grandes catástrofes medioambientales de origen natural o provocado.

A esto se añade una serie de factores que pueden influir en los efectos de dichos riesgos, tales como la dimensión mediática, el dominio del campo electromagnético, la actuación en conflictos simétricos o asimétricos, los desfases tecnológicos, la nueva dimensión del espacio y del tiempo o el uso de la opinión pública y de los medios de comunicación.

Si bien es verdad que el mundo actual, como antes se ha dicho, es en muchos aspectos más complejo e impredecible que su predecesor, no es menos cierto que en la actualidad existen mayores ocasiones de prevenir y de controlar las crisis para impedir la escalada dël conflicto. Este abanico de posibilidades puede ir desde las actividades de diálogo, la diplomacia preventiva, uno de cuyos componentes lo constituye la diplomacia militar, la cooperación y la asociación, que promueven confianza y reducen las principales causas de las crisis o los conflictos, hasta operaciones propias del empleo de la fuerza militar, con mayor o menor fortuna, como las llevadas a cabo en la post guerra fría en Oriente Medio, en el Cáucaso y en los Balcanes. 


\section{El nuevo paradigma estratégico}

En el actual panorama estratégico, en el que existe un mayor número de riesgos y amenazas también aparecen nuevas oportunidades que es necesario utilizar. Los estados deberán contemplar a los actores no-estatales no simplemente como competidores sino también para ser utilizados como instrumentos indirectos de la política $y$, algunas veces como socios y colaboradores. Los estados pueden ganar en influencia lo que pierden en control directo. Cuando ya no tienen el monopolio en las relaciones interestatales su respuesta natural consiste en intentar restaurarlo utilizando agencias no-estatales bajo su control.

La antigua Unión Soviética utilizó tales agencias como «organizaciones del frente». Organizaciones privadas, desde fundaciones islámicas hasta compañías dirigidas por oficiales norteamericanos retirados, suministraron armas y asesoramiento militar a las partes del conflicto yugoslavo, abriendo un amplio abanico de nuevas opciones para los gobiernos de los países.

Algo similar se debe efectuar con los actores no-estatales de carácter autónomo. Fundaciones políticas alemanas, así como importantes fundaciones norteamericanas y organizaciones humanitarias francesas y españolas han edificado su credibilidad en su independencia, estando sus objetivos en armonía con los de la comunidad democrática de la que ellas son una expresión. Por ejemplo, Estados Unidos hubiera tenido menos influencia sobre Pekín si no se hubiera tenido en cuenta la presión de las ONG,s luchando por los derechos humanos en China.

Asimismo, la globalización proporciona a los estados otra importante oportunidad. En lugar de actuar en un sistema donde la diplomacia fue siempre el punto de entrada más importante, la debilidad de las estructuras estatales y el hecho de no ser únicamente intermediarios los estados, hace más fácil para los mismos emplear otros caminos o vías indirectas. Hay un amplio segmento de población cuyos horizontes no son puramente políticos, económicos o diplomáticos sino que se extienden a conexiones de tipo humanitario, educación, cultura o una más libre corriente de información.

\section{La revolución estratégica}

Ya se ha visto bajo qué tipo de orden mundial va a actuar la estrategia, las características más relevantes del entorno de seguridad donde se va a desarrollar así como quienes serán los más importantes actores o entidades estratégicas participantes. 
En el actual contexto mundial, la seguridad es un estado de convivencia caracterizado por una situación de paz, de ausencia de riesgos, retos, amenazas o agresiones y por la estabilidad política, económica y social. El orden garantiza la seguridad mediante el establecimiento de un marco de referencia constituido por un conjunto de principios, valores, actores en presencia, reglas de conducta y normas de comportamiento por las que se rige la convivencia de la comunidad.

Para cumplimentar las condiciones definidas por el orden en su marco de referencia existen diferentes modelos. De entre ellos hay que elegir aquel cuyos procedimientos, métodos, medidas a tomar e instrumentos a utilizar sean los más adecuados para conseguir el más seguro, estable y pacifico estado de convivencia. En definitiva, el escoger un modelo significa optar por la estrategia apropiada.

Como rasgos o características más importantes de lo que se ha expuesto hasta ahora destacan los nuevos actores del orden internacional así como los emergentes riesgos y oportunidades que se hallan en el entorno de seguridad que se ha definido.

En el actual ambiente estratégico, las luchas y enfrentamientos por la posesión del territorio ocurren con menos frecuencia que en los tiempos pasados. Parece necesario analizar más profundamente las nuevas realidades de la incertidumbre y de la complejidad y su relación con el tiempo, la voluntad y el empleo de las masas.

Por otra parte, el conflicto civil, el terrorismo, la secesión, el irredentismo, los actores no-estatales, las armas de destrucción masiva $(\mathrm{ADM})$ y el fundamentalismo constituyen los fenómenos más importantes a tener presente dentro del entorno de las inestabilidades y de las crisis más probables.

La comunidad internacional debe estar preparada para hacer frente a las mortales mezclas de tensiones étnicas, nacionalismos, crímenes transnacionales y la aparición de disputas religiosas, factores todos que salen a la superficie simultánea e inmediatamente después de los conflictos intra e interestatales.

Algunas de las razones principales que está propiciando la revolución en el campo estratégico se apoyan en la indefinición de quien es la comunidad internacional, en la distorsión que producen los medios de comunicación, en la existencia de nuevos factores a considerar y la continua violación de las reglas y conductas éticas y morales que deben regir el comportamiento y la convivencia humana.

El nuevo orden mundial que se está gestando introduce una moderna concepción de la estrategia derivada del enorme salto cualitativo que 
se está sufriendo en los campos de la política, la economía, lo social y lo militar, al final del siglo $\mathrm{XX}$, en relación con el progresivo y menos acelerado cambio que dichos campos han ido padeciendo en su evolución a lo largo de los tiempos.

Ahora la estrategia se define o se establece con propiedad. No es coyuntural sino que su vigencia se halla por encima de los conflictos, acometiendo varios de ellos sin solución de continuidad. Ya no se diseña para una guerra o conflicto determinado sino que se establece para una época histórica caracterizada por un conjunto de circunstancias apropiadas para ser consideradas como determinantes para la definición de un tipo de estrategia. Se le llama la dimensión o el factor temporal de la estrategia.

La dimensión social, la de las comunicaciones, y la de la tecnología junto con las nuevas mentalidades y el dominio del conocimiento constituyen los principales impulsores de la rápida evolución que se está produciendo en el campo estratégico.

De acuerdo con el marco conceptual anteriormente indicado, vamos a exponer seguidamente cómo se puede contemplar el proceso estratégico a que se viene haciendo referencia. El establecer sus diversos componentes supone saber el contenido y la esencia de la estrategia.

\section{Objetivos de la comunidad internacional}

En la línea que se viene argumentando, algunos de los objetivos que puede establecer la sociedad mundial, de hecho, muchos de ellos se hallan en la Carta de las Naciones Unidas, son los que se relacionan a continuación.

- Alcanzar la paz y la estabilidad en todas las regiones del globo.

- Implantar una ética-moral que sea única y aceptada plenamente a nivel internacional.

- Asegurar los valores, principios, e intereses de carácter universal y que sean comunes a las más importantes civilizaciones.

- Garantizar la justicia y respeto de los derechos humanos.

- Promover un desarrollo social y económico sostenible para conseguir una mayor prosperidad para la comunidad internacional.

- Promover los valores democráticos y las libertades fundamentales. 


\section{Criterios básicos}

Dentro de los límites en que se encuadra el orden de seguridad que se ha definido, la doctrina estratégica debe caracterizarse por un sentido de la anticipación al nacimiento de las causas de las inestabilidades, mediante la disuasión previa, el establecimiento de las relaciones adecuadas en el campo del diálogo y la cooperación junto con la firme voluntad de actuar ante cualquier situación.

Es necesario aplicar los mismos criterios para todas las comunidades y pueblos de la tierra, de tal forma que nadie se sienta discriminado. Hay que huir del término «doble rasero». Asimismo, la actuación en el marco multinacional será la forma habitual de operar de la nueva estrategia. De esta manera, los intereses a defender serán siempre comunes y colectivos.

Conviene aprovechar e impulsar el protagonismo de las organizaciones internacionales como foros adecuados para tomar las medidas oportunas en orden a resolver las inestabilidades, las crisis o los conflictos, en su caso.

Se debe considerar a la comunidad internacional como una entidad estratégica única, con el objeto de que la respuesta siempre sea global y cohesionada ante cualquier riesgo o inestabilidad que ponga en cuestión la seguridad internacional.

$\mathrm{Si}$, por un lado, la actuación estratégica tiene que llevarse a cabo dentro de un espíritu de previsión de futuro, que permita ir adaptándose de manera permanente a la evolución que se vaya produciendo en el entorno de seguridad internacional, por otro, es importante sacar el máximo provecho de los adelantos tecnológicos, buscando respuestas rápidas y precisas que reduzcan al mínimo los daños o perjuicios a la sociedad mundial.

Se considera de especial atención la cooperación de los actores noestatales como las Organizaciones No Gubernamentales, agencias, organizaciones internacionales, ... etc, con la tradicional actuación de los estados ya que con ello se incrementará notablemente la eficacia en los resultados.

La visión global sin fronteras de la seguridad y estabilidad internacional será una condición clave para la credibilidad, eficacia y permanencia de la paz en todo el planeta. Las prioridades estratégicas que se establezcan en la resolución de las inestabilidades, crisis o conflictos deben de tener siempre como premisas mas importantes de referencia el respeto a los derechos humanos, a los derechos de las minorías, razones humanitarias, valores democráticos y el gobierno de la ley. 


\section{El nuevo paradigma estratégico}

El mundo actual aboga por la sistematización como forma más adecuada de tratar a la complejidad y por la ambigüedad calculada como futuro modelo de actuación de los actores estratégicos en contraste con el habitual y clásico tratamiento del empleo de la fuerza.

\section{Líneas de acción estratégicas}

Los caminos a seguir para alcanzar los objetivos fijados dentro del marco establecido por la doctrina o los criterios básicos que se acaban de determinar, se definen en base al escenario en que se actúe $\mathrm{y}$ atendiendo al nivel de la inestabilidad, riesgo, amenaza, crisis o agresión. Algunos de los más relevantes pueden ser los que se expresan seguidamente.

La comunidad internacional debe prestar el máximo apoyo al control de armas, al desarme y a la no-proliferación de armas de destrucción masiva (ADM). Es necesario mejorar la seguridad y estabilidad al más bajo nivel posible de fuerzas consistente con la habilidad de los instrumentos que se utilicen para alcanzar la paz mundial. Se promoverán los necesarios esfuerzos políticos para reducir los peligros que se derivan de la proliferación de ADM y de sus medios de lanzamiento.

El diálogo, la cooperación y la asociación constituyen positivos y ejemplares mecanismos que promueven la seguridad y estabilidad en el planeta. El resultado del proceso de Asociación para la Paz (APP), que actualmente se lleva a cabo en el seno de la OTAN, ha alcanzado cotas realmente extraordinarias en el campo de la seguridad.

Con objeto de preservar la paz, impedir la guerra y mejorar la seguridad y estabilidad se buscará la cooperación entre todo tipo de organizaciones internacionales en la tarea de la prevención de conflictos o, en caso de que se desencadene, contribuir al control de la crisis de forma efectiva, consistente con lo establecido en la ley internacional, incluyendo la posibilidad de conducir operaciones en una guerra limitada.

La actuación y estrecha cooperación de los elementos, medios y procedimientos actualmente utilizados por el sistema interestatal, dentro de la ONU o de las organizaciones internacionales con y entre las ONG,s, fundaciones, agencias $\mathrm{u}$ otro tipo de actores no-estatales será establecida como una forma habitual en el nuevo entorno de seguridad que se ha señalado.

El establecimiento de relaciones de bajo perfil en actividades como seminarios, visitas, convivencias, reuniones, enseñanza... etc., condu- 
centes a incrementar las medidas de confianza y seguridad, tendrá una especial importancia dentro de la anticipación activa considerada como una de las características de esta estrategia.

Será de capital relevancia utilizar aquellas áreas del planeta que gozan de una firme y continua paz y seguridad, como focos originadores, promotores y exportadores de estabilidad respecto a las zonas del planeta donde imperan las inestabilidades y los riesgos de potenciales crisis o conflictos.

La promoción del conocimiento, de la ciencia y tecnología, de los medios de inteligencia, de la mejora de la vida social, y de elementos innovadores que optimicen el desarrollo económico así como el incremento del control y cuidado del medio ambiente contribuirá notablemente al mantenimiento y aumento de la prosperidad de toda la comunidad internacional, lo que, sin lugar a dudas, proporcionará una mayor seguridad y estabilidad.

El mantenimiento de la adecuada capacidad militar y una rigurosa disponibilidad y preparación para actuar en la defensa común de los valores universales, junto con la solidaridad política, constituye el instrumento vital de la comunidad internacional para impedir cualquier tipo de coerción o intimidación y para garantizar que la agresión militar dirigida contra cualquier estado o comunidad política nunca sea percibida como una opción que pueda tener éxito.

\section{Escenarios}

En líneas generales, la palabra «escenario» que se va a utilizar engloba no sólo el contexto geográfico sino que también incluye, entre otras cosas, el riesgo, tiempos de respuesta, tendencias de los actores en presencia, características de los medios a emplear, alianzas o acuerdos a considerar, ...etc. Los hechos o acontecimientos que suceden en el mismo tienen una fuerte influencia en la seguridad internacional.

En el proceso lógico que se viene desarrollando, los escenarios que fundamentalmente se consideran son aquellos donde se prevé la aparición o existencia de tensiones, inestabilidades, crisis o agresiones que pongan en tela de juicio o repercutan sustancialmente en la paz y seguridad internacional. Esto no es óbice para que se tenga previsto la actuación en cualquier otro tipo de escenario que en un determinado momento o situación, se considere que reúne condiciones tales que atenten contra la seguridad y estabilidad internacional. 


\section{El nuevo paradigma estratégico}

Esencialmente constituyen zonas de recursos energéticos de carácter mundial, o de acceso a las mismas, donde se encuentran intereses y apetencias principalmente de las grandes potencias, de las organizaciones internacionales o de potencias regionales. Junto a esta clase de escenarios existen otros que se caracterizan especialmente por luchas o enfrentamientos por conseguir la hegemonía o influencia regional.

La franja planetaria de los principales recursos mundiales en los próximos 20 años está situada en la zona señalada en el mapa $\mathrm{n}^{\circ} 2$. En la citada zona se encuentran las áreas donde están acumulados los grandes recursos energéticos: Sudamérica, Golfo de Guinea-Grandes Lagos, Oriente Medio y la cuenca del mar Caspio.

En esta franja sólo se encuentra, de forma excéntrica, una gran potencia, Rusia. El resto de las grandes potencias se halla fuera de la misma. Es previsible que, en los próximos años se asista a una importante competencia entre las mismas para acceder a dichos recursos. Ello provocará tensiones y relaciones inestables de carácter internacional, con independencia de los conflictos y enfrentamientos que puedan ocurrir entre los diferentes países situados en el interior de la zona.

A estos efectos y dentro del entorno de seguridad expresado anteriormente, las zonas del globo más proclives a la existencia o al surgimiento de focos de riesgo con repercusión en la estabilidad planetaria corresponden a Oriente Medio, los Balcanes, Africa Subsahariana, la cuenca del mar Caspio, el Sur de Asia y el Este de Asia (mapa $\mathrm{n}^{\circ} 3$ ).

\section{Oriente Medio}

Esta región se encuentra sometida a grandes convulsiones consecuencia fundamentalmente de las razones que se relacionan a continuación.

Por un lado, las relaciones entre Israel y el mundo árabe se hallan en permanente situación inestable, con independencia del proceso de paz de Oriente Medio, como consecuencia del no reconocimiento de las fronteras, del establecimiento definitivo del Estado palestino, de las disputas judío-islámicas sobre la propiedad de los Santos Lugares o de los problemas derivados de "la escasez del agua.

Por otro, se encuentra la eterna rivalidad entre los países musulmanes de la zona en su búsqueda de alcanzar la hegemonía regional, 


\section{Jesús Rafael Argumosa Pila}

en la responsabilidad de la custodia de los Santos Lugares del Islám o el permanente conflicto intra-islámico provocado por el cisma sunnita-chiita. En especial, la lucha por el liderazgo en la zona por parte de Irán, Irak, Arabia Saudí y Siria puede ocasionar violentos enfrentamientos y consecuencias realmente graves para la estabilidad internacional.

El proceso de plena independencia de Líbano con la retirada de las fuerzas israelíes y sirias continúa produciendo fricciones entre los árabes y los israelíes debido a las dificultades que existen para controlar y regular la convivencia entre los diferentes grupos religiosos y étnicos que habitan en el país, desde los cristianos maronitas hasta los drusos pasando por los sunnitas y chiitas.

El problema kurdo sigue constituyendo una fuente de crisis e inestabilidades en aquellos países donde mayormente se halla este pueblo, en particular entre Turquía, Irak, Irán y Siria. La posible creación de un estado kurdo choca de lleno con los intereses de los países antes mencionados cuyo objetivo final consiste en librarse de ellos a ser posible haciendo que emigren a otros lugares fuera de la región.

La situación representada puede producir unos riesgos derivados tanto de la rivalidad árabe-israelí como de las disputas entre los países musulmanes, dando lugar con gran frecuencia a enfrentamientos o a conflictos fratricidas dentro de la comunidad islámica que, en función de la importancia estratégica de la zona, puede implicar, y de hecho, ha estado implicando los últimos años a las grandes potencias.

Con mucha probabilidad, varios estados de la zona disponen de armas de destrucción masiva y de sus medios de lanzamiento. Posiblemente la capacidad nuclear de Israel pueda encontrar a corto plazo su contrapeso en algunos países del área como pueden ser Irán o Irak.

Las fuerzas armadas convencionales de estos países responden a unas características y entidad muy semejantes a las naciones occidentales. A medio plazo pueden disponer de tecnología emergente y con gran probabilidad estén dotadas de las capacidades militares de despliegue y movilidad, enfrentamiento eficaz, supervivencia de fuerzas y de infraestructura y mando, control y comunicación.

\section{Los Balcanes}

La cuestión balcánica ha estado presente en todas las grandes conflagraciones del continente europeo. A pesar de pertenecer toda su 


\section{El nuevo paradigma estratégico}

ribera sur al Mediterráneo, la influencia y repercusión de los acontecimientos de los Balcanes siempre se han manifestado con enormes consecuencias en la estabilidad del Centro y Este de Europa, afectando grave y poderosamente a la unidad europea.

Desde el Adriático hasta las costas del mar Negro y desde el Mediterráneo a la cuenca del Danubio, esta zona constituye una impredecible encrucijada que está sujeta a continuas convulsiones de orden étnico, religioso, nacionalista y de delimitación de fronteras. De hecho, aún no se ha conseguido, de forma clara, real y creible, una convivencia pacífica dentro de las comunidades multiétnicas, multireligiosas o multinacionalistas que habitan en los Balcanes. Las posturas de los principales países europeos han estado enfrentadas en numerosas ocasiones en relación con el territorio balcánico.

En estos momentos de cambio de siglo, la desaparición de Yugoslavia y la reciente guerra de Kosovo han vuelto a desencadenar los demonios balcánicos. A pesar de la victoria de la OTAN sobre el Ejército serbio, incluyendo su abandono del territorio kosovar, la misión de la Fuerza de Seguridad para Kosovo (KFOR), compuesta por unos efectivos cercanos a 50.000 militares de más de 30 países (el mayor contingente lo han puesto los 16 miembros de la Alianza Atlántica), de supervisar la retirada serbia, garantizar la vuelta de los refugiados y evitar un rebrote de violencia revanchista contra la minoría serbia, no será nada fácil.

Por otra parte, en el lado civil, la ONU será la principal responsable del establecimiento de una administración internacional con la denominación de Misión de las Naciones Unidas en Kosovo (UNMIK). Las tareas más importantes serán facilitar el reasentamiento de los. refugiados, iniciar las tareas de reconstrucción y crear las condiciones políticas y sociales para que se pueda establecer un autogobierno en la provincia.

Junto a ello, el Pacto de Estabilidad en los Balcanes, al que se le dio carta de naturaleza con la Declaración de Sarajevo, el pasado 30 de julio, firmada por un centenar de lideres mundiales, que fija el marco de democracia, desarrollo y seguridad de la zona, constituirá el escenario adecuado para la integración del Sureste de Europa en un continente donde las fronteras deben permanecer inviolables.

Sin embargo, no es sencillo cambiar el rumbo de la ecuación balcánica, con una larga historia cercana a los mil años, en tan sólo unos pocos lustros. Con un alto grado de probabilidad, seguiremos asistiendo, en los primeros años del próximo milenio, a inestabilidades y crisis en los Balcanes. No únicamente el futuro de Kosovo, sino 
también el de Macedonia, Montenegro y especialmente Serbia se hallan en una total incertidumbre.

Aunque países limítrofes como Austria, Hungría, Bulgaria, Rumania y Grecia mantengan hasta ahora una posición moderada y de gran sensatez, las reivindicaciones en todo el entorno balcánico aún no están cerradas. Cualquier explosión de tipo étnico, nacionalista o religioso en esta zona puede afectar gravemente tanto a la seguridad interna de Europa como a la estabilidad internacional fundamentalmente en las relaciones con el mundo islámico o con el mundo eslavo.

Las fuerzas militares convencionales de la zona presentan unas características de tecnología media-baja pero que resultan ciertamente eficaces en el terreno en que se mueven. A excepción de Grecia y Turquía dotadas de medios de corte occidental, los demás Ejércitos tienen material procedente de la antigua Unión Soviética con notables problemas tanto de abastecimiento como de mantenimiento. Disponen de las capacidades militares de despliegue y movilidad, supervivencia de fuerzas y de infraestructura.

\section{Africa Subsahariana}

Africa Subsahariana se caracteriza por las turbulentas y continuas crisis que asolan a una parte importante de la región y que están produciendo una enorme violencia y constantes actuaciones contra los derechos humanos.

Las Iniciativas de Ayuda a la pacificación y estabilización de estos países de Africa Subsahariana, que han iniciado, en diversos campos, algunos países occidentales, encabezados por Francia y Estados Unidos, no han dado los resultados que se esperaban por querer ir demasiado deprisa. Africa es un viejo continente que tardará en alcanzar los standars de Occidente, de forma lenta y progresiva.

De los tres conjuntos de países que se distinguen en esta región, el del Golfo de Guinea, liderado por Nigeria, el de los Grandes Lagos donde sobresale la República del Congo y el de Africa Austral pilotado por Sudáfrica, el último de ellos es el que ha conseguido un desarrollo político, económico y social más consolidados y equilibrado.

Aunque la zona del Golfo de Guinea está sufriendo un notable crecimiento económico y social, especialmente debido a la explotación de los yacimientos de hidrocarburos existentes en su subsuelo, lo cierto es que se halla sometida a continuos conflictos de naturaleza funda- 


\section{El nuevo paradigma estratégico}

mentalmente étnica. Aùn así, siguen existiendo amplios sectores de la población por debajo del nivel de la pobreza.

$\mathrm{Su}$ desarrollo político es desequilibrado. Junto a países que están dando firmes pasos hacia la democracia como Guinea Conakry, otros como Congo Brazzaville siguen siendo regímenes dictatoriales. En el intermedio existe una amplia gama de distintos niveles de gobiernos con diferentes grados de restricciones políticas.

Nigeria, gran potencia de la zona, tampoco constituye un modelo a seguir debido a los permanentes bandazos que está dando en la consolidación democrática. En pocas ocasiones ha conseguido un aceptable nivel de pluralismo político y libertades individuales.

En la región de los Grandes Lagos, la situación también se caracteriza por inestabilidades crónicas y violaciones permanentes de los derechos humanos y del respeto a las minorías. La república del Congo no ha conseguido el nivel de estabilidad política que le pueda permitir tener un liderazgo claro en la zona. A pesar de la existencia de países como Tanzania y Kenia con un desarrollo político más avanzado, la mayor parte de las naciones de la zona disfrutan de regímenes de tipo anárquico enraizados en las costumbres y diferencias étnicas $\mathrm{y}$ tribales.

El nivel de vida de la mayor parte de la población se halla cerca de los umbrales de la pobreza, con independencia de la gran riqueza del subsuelo en minerales estratégicos y diamantes, como consecuencia de la desastrosa política llevada a cabo por la mayoría de los gobiernos en el sentido de la distribución irracional de los beneficios económicos de cada nación.

Aunque el Africa Austral se halla en un nivel de desarrollo político, económico y social superior a las dos regiones antes mencionadas, lo cierto es que también existen crisis y tensiones en algunos países de la zona. Antiguos conflictos como los de Angola, Mozambique, Namibia y aún los derivados del apartheid de Sudáfrica, todavía no han cicatrizado sus heridas.

El desarrollo democrático, económico y social alcanzado por Sudáfrica está sirviendo de paradigma y de manto amortiguador a cualquier inestabilidad o crisis que pudiera ocurrir en la zona. Su influencia sobre el resto de los países está contribuyendo de forma notable a crear las condiciones de paz y de estabilidad en el área.

De forma global, los riesgos que se perciben con más probabilidad en el Africa Subsahariana son aquellos procedentes de disturbios tribales o de luchas de poder político entre fracciones de una misma etnia que se plasman con cierta frecuencia en golpes de estado o conflictos 
con una alta tasa de mortandad. Sus consecuencias pueden crear inestabilidades y extenderse a países o zonas limítrofes que pongan en evidencia los intereses de seguridad mundial.

La mayor parte de los Ejércitos de estos países son de pequeña entidad y su característica más relevante reside en que disponen principalmente de armamento ligero, individual y colectivo, en unas condiciones de funcionamiento y mantenimiento realmente deficientes. Apenas tienen armamento pesado y, si lo tienen, el abastecimiento de munición es muy precario. En estas condiciones las capacidades operativas son ciertamente bajas.

La excepción a estas características la constituye Sudáfrica que disfruta de un ejército mucho más cercano al de los países occidentales con un estado de operatividad y eficacia de nivel medio. Dispone de tecnología emergente con adecuadas capacidades operativas de despliegue y movilidad, supervivencia de fuerzas y de infraestructura y sostenimiento incluyendo la logística y la rotación de fuerzas así como de un aceptable nivel de mando, control y comunicaciones.

\section{Cuenca del Caspio}

El entorno del Cáucaso se caracteriza por estar sujeto a fuertes presiones tanto en el lado oriental como en el occidental, distinguiéndose por constituir una zona colchón entre dos comunidades cuyas civilizaciones responden a criterios y valores culturales, éticos y sociales muy distintos.

De esta forma, en sus sociedades conviven dos tendencias contra- puestas. Por una parte, se halla la atracción: occidental, donde la democracia, la economía de mercado y las libertades individuales están muy arraigadas. Por otra, las estrechas relaciones con una forma de vida, historia y tradición enraizadas en una cultura eslava y milenaria, de una parte sustancial de la población, produce una inclinación hacia otro tipo de valores e ideales.

Junto a ello, sufren profundas divisiones internas de carácter étnico, religioso o racial así como sangrientas disputas fronterizas. No sólo en el nivel interestatal, especialmente entre Azerbaiyan, Armenia y Georgia sino además en el ámbito intraestatal como ocurre en Chechenia, Abjasia o Ingushetia.

En concreto, naciones o territorios como Armenia, Nagorno-Karabaj u Osetia del Sur están desgarrados por la ambivalencia permanente en que están viviendo sus comunidades. Esta realidad, unida a los 


\section{El nuevo paradigma estratégico}

intereses tan diferentes de los países limítrofes ha producido una continua situación de inestabilidad y desordenes sociales que han provocado varias intervenciones de fuerzas militares bajo la bandera de la ONU o de la OSCE.

Las actividades llevadas a cabo en el proceso de Asociación para la Paz y dentro del marco del EAPC de la OTAN no han conseguido evitar los recelos hacia el mundo occidental ni tampoco han resuelto el grave problema de identidad nacional que arrastran los países de esta zona. La afloración de nacionalismos y de continua disgregación de países ha conducido a un permanente cambio de fronteras poniendo en peligro la misma existencia de los estados.

En este entorno se halla el irredentismo existente en la península de Crimea, territorio ucraniano con una numerosa población de etnia rusa que ha expresado su deseo de formar parte de Rusia. Una guerra o conflicto entre Ucrania y Rusia afectaría directamente a Alemania y a gran parte de Europa.

En la cuenca del mar Caspio, algunas repúblicas como Kazajstán y Turkmenistán están alcanzando en los últimos años un nivel socioeconómico relativamente bueno, de forma general, consecuencia del desarrollo económico procedente de la explotación de los enormes recursos energéticos existentes en la zona. Sin embargo, otras como Uzbekistán, Tajikstán y Kirgyzstán, se encuentran sometidas a unas condiciones sociales y de forma de vida ciertamente ínfimas.

La situación política y de seguridad de la zona es especialmente preocupante. Gran parte de las diferentes minorías existentes en las cinco repúblicas musulmanas centroasiáticas no disfrutan de las mínimas condiciones de respeto a los derechos humanos, libertad de expresión o de igualdad ante la ley. Este es uno de los principales motivos de la existencia de continuas tensiones y conflictos en el área que puede obligar, con gran probabilidad, a la realización de operaciones multinacionales en apoyo de la paz y de la estabilidad.

Las fuerzas militares de los países de este escenario se encuentran en estado deficiente. A expensas de tener en cuenta las importantes fuerzas nucleares rusas, en el ámbito convencional, al no haber disfrutado la zona de un desarrollo económico adecuado, el nivel de tecnología y de poder de adquisición tanto del sector público como del privado es muy bajo. En consecuencia, los medios militares de los ejércitos del área son realmente muy modestos y dotados de una escasa tecnología. Apenas llegan a tener unas mínimas capacidades de despliegue y movilidad, de supervivencia de fuerzas y de sostenimiento. 


\section{Sur de Asia}

La crónica tensión entre India y Pakistán acerca de Cachemira, que ya ha provocado dos guerras entre ambos países desde su independencia en 1947, continúa existiendo a finales del siglo XX, con el agravante de que los dos países han efectuado pruebas nucleares en una demostración disuasiva de fuerzas sin precedentes.

El que las dos potencias nucleares mantengan unas tensas relaciones y grandes diferendos es de por sí un problema grave para la paz y estabilidad planetaria. Si a esto se añade que otras potencias nucleares, más potentes, y con más peso en la seguridad mundial, China y Rusia, mantienen posturas diferentes respecto al conflicto indo-pakistaní, apoyando la primera a Pakistán y la segunda a India, el contencioso adquiere mayor gravedad y peligrosidad.

A mayor abundamiento, el litigio fronterizo chino-indio en territorio próximo a Cachemira junto a la posible implicación de Afganistán, ya sometido a una cruenta guerra civil, y de algunas repúblicas musulmanas centroasiáticas introducen nuevos elementos de riesgo y de posible incremento o expansión del conflicto inicialmente centrado en Cachemira.

El proceso de consolidación de la democracia en la India continúa sufriendo algún sobresalto que provoca disturbios y desórdenes internos no deseables para el estado. Asimismo, las corrupciones y luchas dentro de Pakistán fundamentalmente entre partidos políticos de carácter religioso y étnico no favorecen la estabilidad del régimen. Por otra parte, la situación económica en ambos países, que no ha dejado de deteriorarse en los últimos años, incrementa la inestabilidad en el área.

Además, la existencia de más de 100 millones de musulmanes dentro de India, con un «status» de segundo orden dentro del estado, aumenta, por un lado, los problemas de control y estabilidad interna en el territorio de la península indostánica y, por otro, produce sentimientos anti-indios en gran parte de la comunidad musulmana internacional, principalmente en las zonas próximas a dicha península que pueden provocar inestabilidades en la paz y seguridad global.

Otros países de la zona como Bangladesh y Sri Landa siguen madurando en sus procesos democráticos, aunque con diferente ritmo e intensidad. Bangladesh está consiguiendo un notable desarrollo económico y social sin grandes traumas. Sin embargo, en Sri Landa la guerra civil entre el gobierno y los separatistas tamiles, ha continuado influyendo negativamente tanto en la vida política como en la economía del país. 


\section{El nuevo paradigma estratégico}

Los ejércitos de este escenario tienen entidades, dimensiones y capacidades de muy diversa índole. En el campo nuclear, se hallan las fuerzas nucleares de India y Pakistán a las que no son ajenas las de China. En el entorno convencional, las fuerzas militares tanto de India como de Pakistán, destacan no sólo en su dimensión sobre el resto de los países sino también en su nivel tecnológico. Así, mientras las fuerzas de estos dos países disfrutan de un desarrollo tecnológico aceptable, disponiendo de las capacidades de despliegue y movilidad, supervivencia de fuerzas y de infraestructura y sostenimiento, las de otros países del área como las de Bangladesh o Bhután se hallan en unas condiciones realmente precarias. En el intermedio, más bien cerca de los dos últimos se encuentran las de Sri Landa.

\section{Este de Asia}

Desde la Rusia asiática hasta Indonesia y desde la China profunda hasta Australia, este escenario encierra una serie de religiones, civilizaciones, culturas y problemas de seguridad totalmente dispares.

Aunque los Estados Unidos tienen una presencia militar en la zona de 100.000 efectivos, mantiene alianzas militares con Japón, Corea del Sur, Filipinas, Australia y Tailandia y apoya el diálogo regional de la ASEAN, las tensiones en la península de Corea permanecen como las principales amenazas a la paz en el Este de Asia.

Las conversaciones cuatripartitas entre los Estados Unidos, China, Corea del Norte y Corea del Sur, no están consiguiendo ningún resultado positivo. Corea del Norte sufre un enorme desastre económico al mismo tiempo que dispone de medios de lanzamiento de misiles con posibilidades de portar medios nucleares.

En cuanto a China y a pesar del elevado nivel de crecimiento que ha disfrutado en los últimos años, aún sufre los graves problemas internos de Tibet y Taiwan así como el brote de los nacionalismos como el de los igures musulmanes del territorio del Noroeste. En concreto, las pretensiones de China de incorporar a Taiwan a su soberanía pueden producir graves problemas en la seguridad internacional en los que estarían implicados, como mínimo, tanto los Estados Unidos como Japón.

Por otro lado, China mantiene tensiones fronterizas sin resolver con India, Vietnam y con los países ribereños del Mar de la China Meridional, así como una diáspora muy activa en varios países del Sudeste Asiático que están ocasionando focos de inestabilidades con 
repercusiones importantes en la seguridad internacional. A ello se añade el problema de las islas Diaoyo situadas en las aguas reclamadas tanto por Pekín como por Tokyo.

En realidad, las pretensiones actuales del país de la Gran Muralla se centran en dos grandes temas. Por un lado, como lograr un equilibrio de poder en la región del Asia-Pacifico, en especial de cara al futuro protagonismo tanto de los americanos como de los japoneses. Por otro lado, cuales son sus posibilidades de desplegar sus fuerzas militares para asegurar los recursos que requiere su asombroso crecimiento económico.

Con respecto al contencioso ruso-japonés en torno a las islas Kuryles y al litigio fronterizo, ahora aletargado, entre China y Rusia, no se pueden perder de vista las graves repercusiones en la seguridad y estabilidad de la zona que puede producir la incierta e inestable evolución del desarrollo político y económico de Rusia.

Indonesia está atravesando difíciles momentos que están poniendo en peligro la estabilidad del país, el más poblado del mundo musulmán. La sucesión del autoritario y corrupto régimen de Suharto aún no está resuelta. Por otra parte, la brutal represión llevada a cabo por el Ejército de Indonesia en Timor Oriental, antigua colonia portuguesa ocupada y anexionada por este país en 1975, añade más incertidumbres a la credibilidad del actual gobierno ante la comunidad internacional.

Las fuerzas militares de este entorno presentan características y capacidades muy distintas. Por un lado, sobresalen las fuerzas nucleares chinas y rusas. Dentro del ambiente convencional, existen Ejércitos de grandes dimensiones como el chino y el ruso, con un desarrollo tecnológico medio-alto, pero con ciertos problemas de funcionamiento, junto a los de Japón, Corea del Sur o Taiwán, más pequeños pero disfrutando de una alta tecnología.

Con independencia de la posible existencia de armas de destrucción masiva y de sus medios de lanzamiento por parte de Corea del Norte, en el extremo de menor desarrollo se hallan otros ejércitos como el de Indonesia o Filipinas. Entre sus capacidades sobresalen las de despliegue y movilidad, enfrentamiento, supervivencia de fuerzas y sostenimiento.

\section{Instrụmentos}

Como mencionábamos en el marco conceptual, se trata de encontrar qué tipo de medios tienen que emplear los actores estratégicos para 


\section{El nuevo paradigma estratégico}

conseguir los objetivos que se han señalado, de la forma que se ha indicado y en los escenarios expresados. De esta manera, se cierra el proceso de la estrategia que se está definiendo.

Sería prolijo enumerar y desarrollar en detalle todos los instrumentos que se tienen que emplear para que la estrategia planetaria que se ha expuesto en este ensayo se pueda llevar a cabo. En este momento únicamente nos limitaremos a indicar que los más importantes campos a los que deben pertenecer los instrumentos o medios a utilizar son los de la política, la diplomacia, la economía, el cultural, el social y el militar.

A modo de ejemplo, y hablando sólamente del campo militar, la comunidad internacional, para hacer frente con eficacia y efectos resolutivos, de forma general, a los requerimientos de la amplia gama de conflictos que se pueden presentar y teniendo en cuenta la diversidad de Fuerzas Armadas que pueden intervenir, debería disponer de unas fuerzas militares que incluyeran, al menos, los tres niveles de capacidades que se mencionan a continuación.

El nivel de las capacidades propiamente operativas, representadas por el enfrentamiento eficaz, capacidad de despliegue y movilidad, la supervivencia de fuerzas y de infraestructura y el sostenimiento, incorporando la logística y la rotación de fuerzas. El de los catalizadores, como integradores del desarrollo de los anteriores en el campo de las operaciones multinacionales que son la interoperabilidad, el uso de la tecnología avanzada apropiada y el mantenimiento de la superioridad de la información. Como tercer nivel, se encuentran los multiplicadores de fuerzas constituidos fundamentalmente por el mando, control y comunicación, la inteligencia y el reconocimiento.

\section{En los albores del siglo XXI}

Bien es verdad que estamos inmersos en una indefinición e indeterminación del pensamiento estratégico, pero no es menos cierto que este fenómeno no es nuevo en el ámbito estratégico. En periodos históricos de profundos cambios como el de la reforma protestante, la Revolución Francesa o el final de la Segunda Guerra Mundial, siempre se ha asistido a momentos de reflexión y análisis al objeto de encontrar o diseñar el nuevo orden, con las adecuadas directrices políticas y de seguridad que constituyen la fuente para el establecimiento de la estrategia apropiada. 
Por otra parte, después de haber pasado por un largo periodo de guerra fría donde se había establecido un esquema estratégico sólido y estable como consecuencia de que estaban claramente definidos los actores, los escenarios, las fronteras y el potencial adversario, es razonable pensar que las incertidumbres y complejidades de este final de siglo no favorecen inicialmente el establecimiento de una doctrina estratégica sólida, coherente y con visión de futuro.

Los parámetros de medida que han aparecido o están naciendo como pueden ser la aplastante utilización del empleo de los medios en el caso de los Estados Unidos, la inducción a la parálisis de la decisión empleada por Hassan Hussein o Milosevic, la coexistencia de la globalización y de la fragmentación, las asimetrías de los actuales y previsibles conflictos, el uso de la dimensión social frente a la evolución tecnológica, la entrada en la era del conocimiento, la consideración del discutido concepto de daños colaterales, el empleo del doble rasero o la dificultad de identificar al ente de la comunidad internacional, influyen poderosamente en el diseño y establecimiento de la estrategia planetaria.

Asimismo, la invocación a los principios morales en algunos conflictos, las características de la doctrina de seguridad que está emergiendo, los errores en la aplicación de una estrategia previamente diseñada, como ocurrió en la reciente guerra de Kosovo, la frecuente coincidencia de los focos de tensión con la frontera entre civilizaciones o la relativamente fácil predisposición a considerar al nacionalismo como identidad étnica, histórica y cultural para, a continuación, concederle la plena independencia, da lugar a realizar un gran esfuerzo en orden a efectuar un cambio de mentalidad por toda la comunidad internacional para asimilar con la suficiente convicción y solidez dichos conceptos.

En este contexto es donde se vislumbra una nueva estrategia para una nueva era. Todo ello constituye una apasionante apuesta de futuro que, junto a términos o sucesos tales como el orden mundial sin fronteras, el dominio del tiempo, la explosión étnica, las razones humanitarias o la rapidez de los acontecimientos y de las informaciones que desafían las capacidades intelectuales del hombre, produce verdaderamente una revolución estratégica.

El establecimiento del nuevo paradigma estratégico de los primeros años del siglo XXI, que se ha intentado exponer, y con el que se pretende responder con responsabilidad y eficacia a los retos y riesgos del nuevo ambiente de seguridad internacional, se fundamenta, en 
esquema y en una primera aproximación, en los supuestos que se relacionan a continuación.

El reconocimiento de un nuevo orden mundial sin fronteras, con las características que se han indicado.

La existencia de una zona del globo, en la que se hallan los más importantes recursos energéticos de los próximos años, donde se van a centrar las principales competencias, tensiones e inestabilidades, fundamentalmente entre las grandes potencias, las más relevantes organizaciones internacionales y las potencias regionales.

Una sistematización de esfuerzos a realizar por los diversos actores estratégicos de la comunidad internacional buscando la convergencia de esfuerzos frente a la complejidad.

Se efectuará una transición del sistema de relaciones internacionales basado en el equilibrio de poder, fundamentado en las relaciones entre las grandes potencias, al del poder político, cuya peso se encuentra en las relaciones entre diversas organizaciones internacionales, incluidas alianzas.

Existirá un concepto dimensional-temporal de la estrategia en el que el establecimiento de la misma, por una parte, tendrá presente un gran número de factores que hasta ahora no se consideraban, $y$, por otro, tendrá una duración en el tiempo que le permita ir solucionando las posibles crisis y conflictos conforme se vayan presentando.

El concepto de la unidad estratégica mundial será entendida como la respuesta de toda la comunidad internacional, como un sólo bloque, ante cualquier hecho, fenómeno o acontecimiento que afecte a la paz y estabilidad mundial.

La utilización habitual, por parte de la ONU, de las organizaciones internacionales, y de los actores no-estatales..

Se identificarán focos regionales de estabilidad que se utilizarán como proyectores de seguridad, especialmente en su entorno cercano. Precisamente esa proyección radiante de estabilidad de varios focos con sus diversos alcances, estableciendo solapes entre zonas, puede permitir que llegue la paz y la seguridad a todo el planeta.

Se considerará a la ambigüedad calculada como elemento o medida a tomar, en especial en aquéllas ocasiones o situaciones en que determinados actores estratégicos pretenden conseguir la parálisis de la decisión.

El concepto de anticipación activa será un permanente elemento de referencia en este paradigma. Es necesario reconocer y abortar las crisis antes de que ocurran. 
La estructura estratégica que se establezca debe ser lo suficientemente flexible como para ser capaz de adaptarse a los permanentes y acelerados cambios que sufre el actual y previsible marco de seguridad mundial.

En este ámbito, siempre se tendrá en cuenta que el centro de gravedad de la actuación de esta estrategia de la integración, se encuentra en sus componentes principales de la política, la diplomacia, la economía, lo social y lo militar. Sobre ellos operan, con mayor o menor intensidad, otras acciones de tipo cultural, humanitario, control de población, étnico, educación, medio ambiental, normativo...etc, que completan o complementan la eficacia del proceso estratégico.

En el contexto en el que nos hemos situado, parece conveniente recordar que se tiene un reciente ejemplo y modelo de la forma de establecer una estrategia por parte de una colectividad cuando esta se caracteriza precisamente por la búsqueda de unos intereses y valores comunes. Nos referimos al actual Concepto Estratégico de la OTAN, que data del pasado mes de abril. Su confección se ha realizado en un tiempo ligeramente superior al año.

Es en esta línea donde las Naciones Unidas, como representante de la comunidad internacional, debiera iniciar el trabajo y los estudios necesarios para encontrar el método o el procedimiento de conseguir la paz y seguridad en el planeta en el actual ambiente de seguridad mundial. En definitiva, se trataría de determinar con rigurosidad, solidez y coherencia los componentes del proceso estratégico que aquí se han definido.

Por último, con estas primeras reflexiones, plasmadas en el paradigma estratégico que se ha expuesto, sólo se pretende aportar alguna ayuda y dejar una ventana abierta para el establecimiento de la estrategia planetaria del inicio del próximo siglo, en orden a alcanzar la tan ansiada paz y seguridad que necesitan y merecen todos los pueblos de la tierra. 


\section{El nuevo paradigma estratégico}

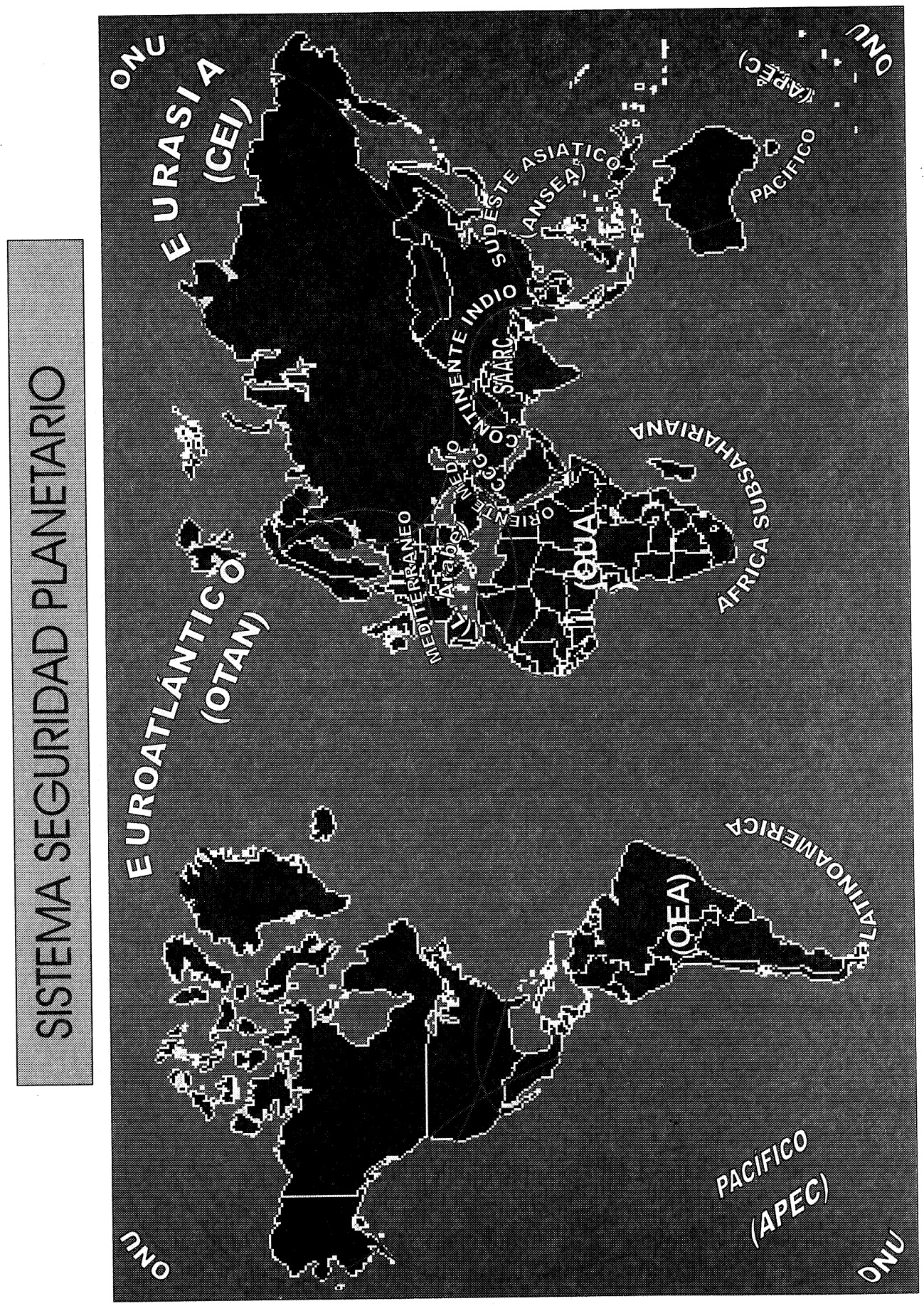


Jesús Rafael Argumosa Pila

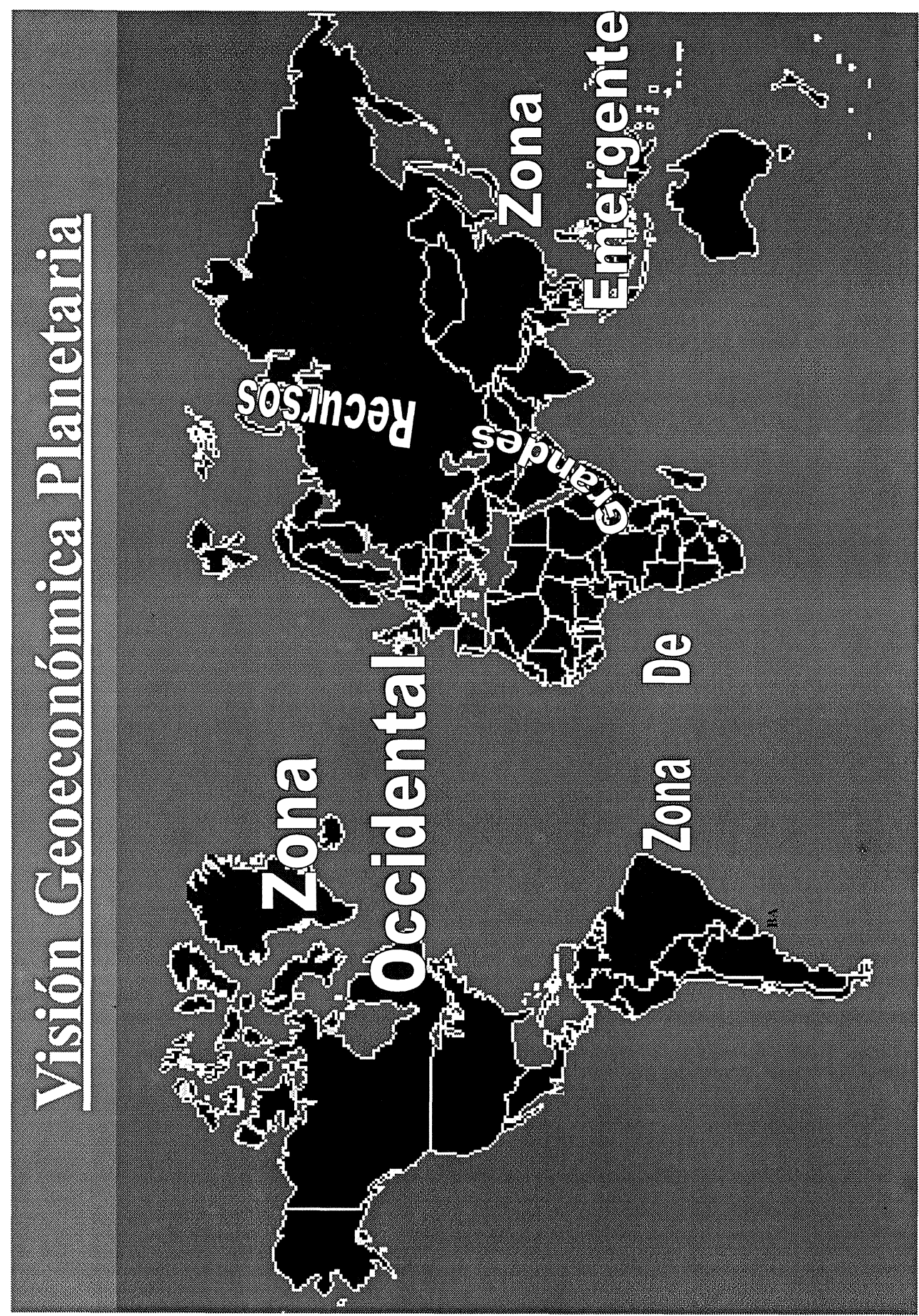




\section{El nuevo paradigma estratégico}

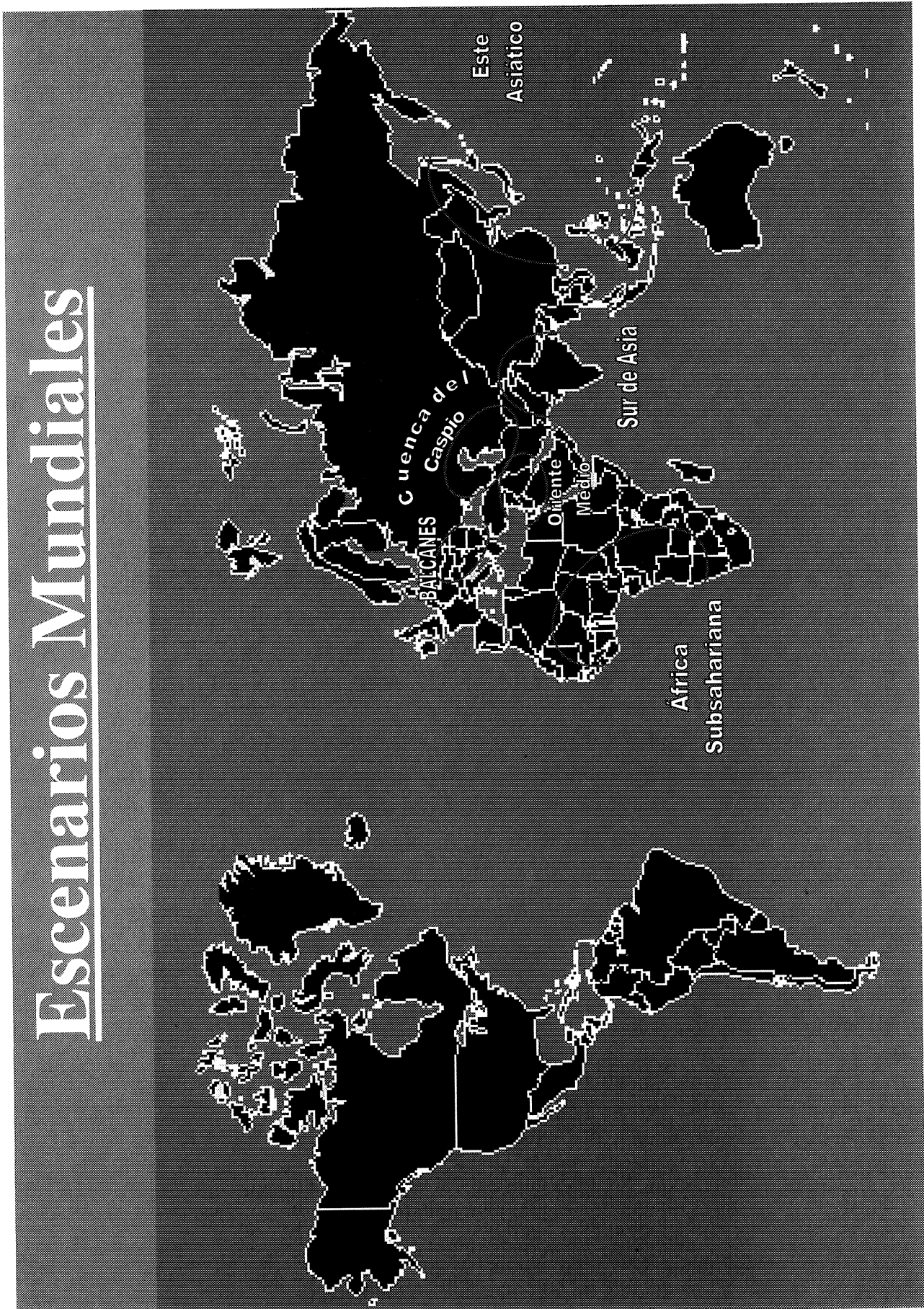




\section{Conflictos actuales más importantes}

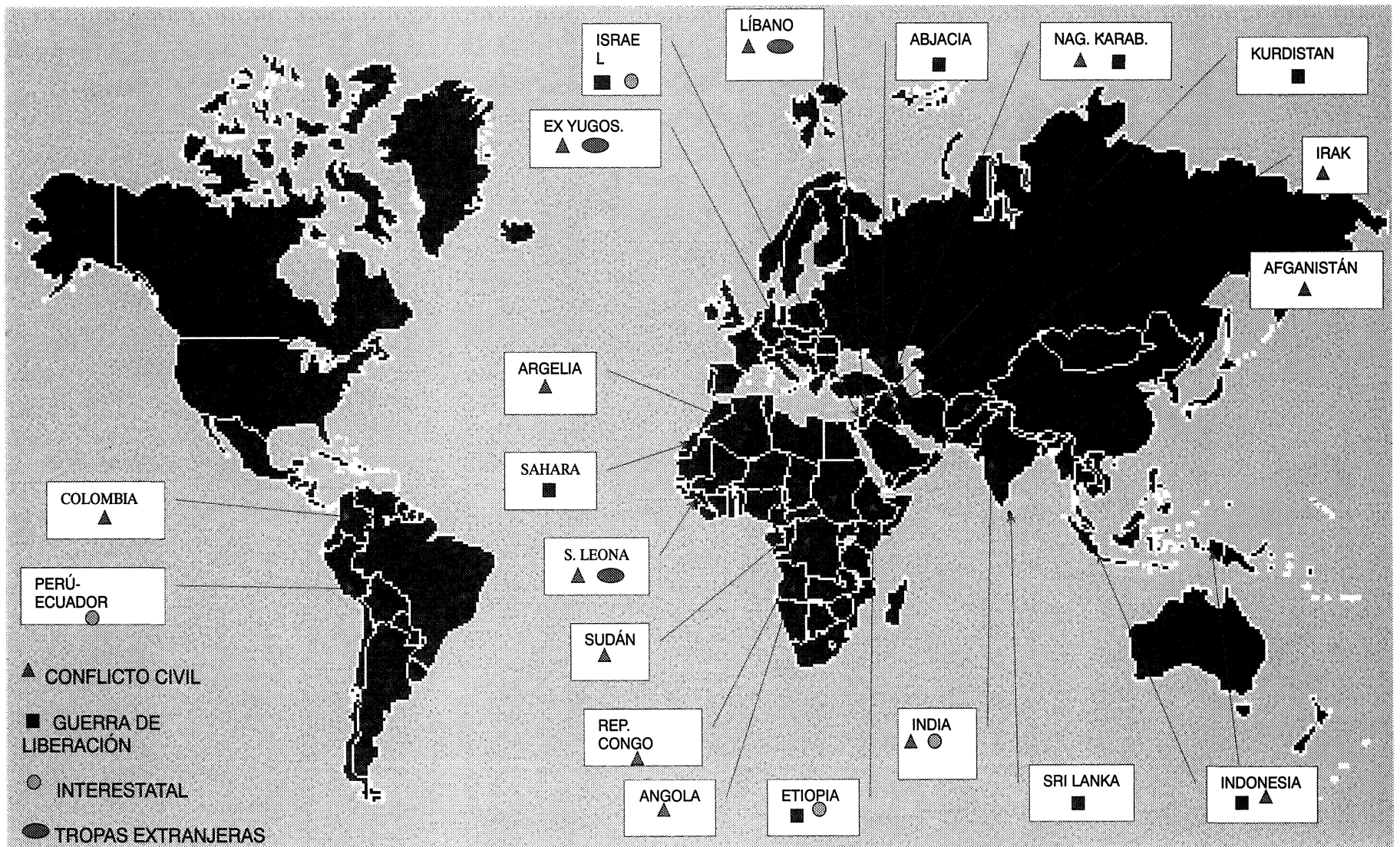

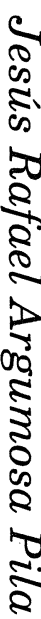




\section{El nuevo paradigma estratégico}

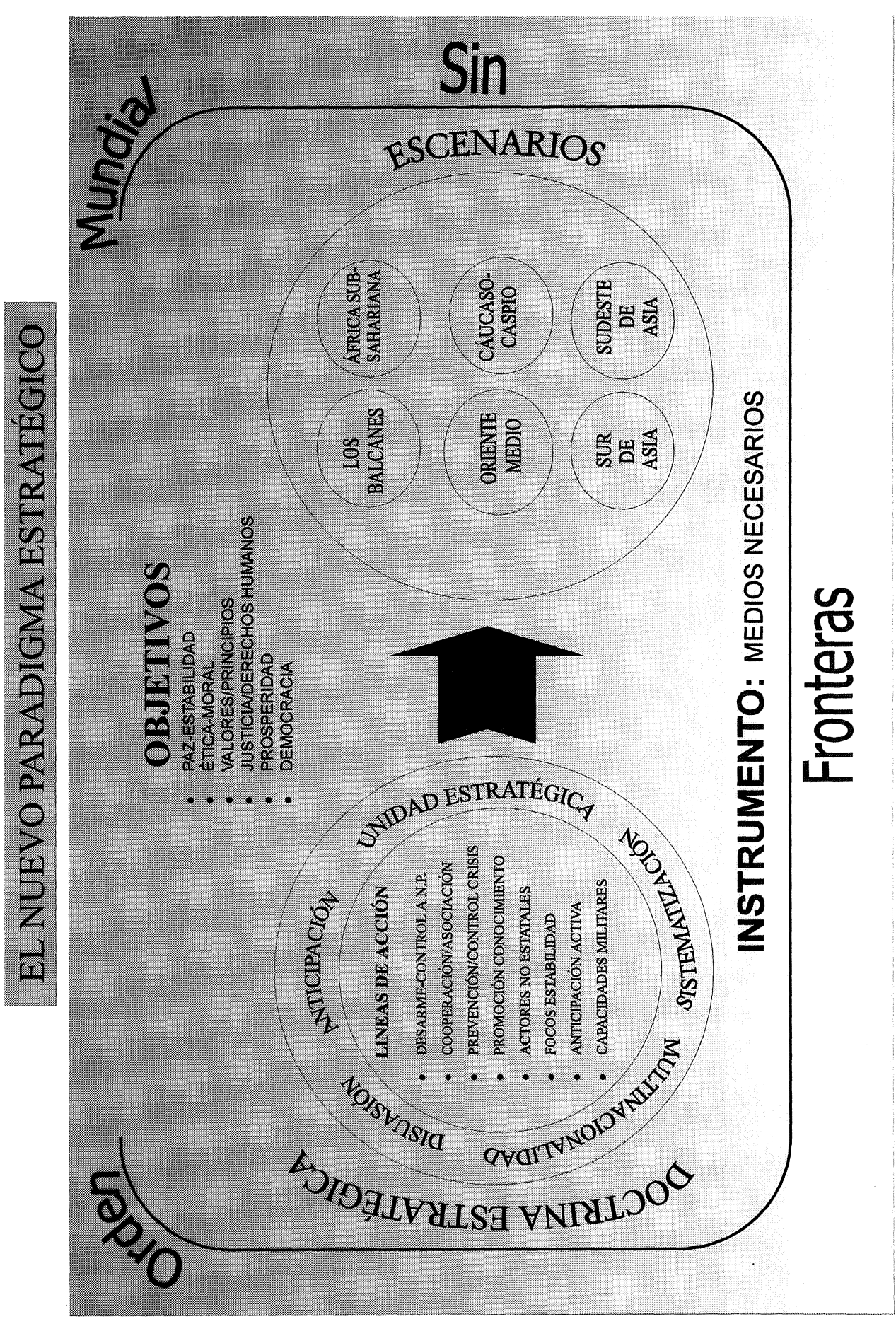




\section{Bibliografía}

Tendencias estratégicas en el umbral del siglo XXI. Jesús R. Argumosa PiLA. REVISTA EJERCITO n. ${ }^{\circ}$ 673. Junio 1996.

A strategy of chaos. Lt.. Col. P.H. Liotta, USAF. STRATEGIC REVIEW. Spring 1998.

Un nuevo orden mundial sin fronteras. Jesús R. ARgumosa PiLA. REVISTA EJERCITO n. ${ }^{\circ}$ 689. Junio 1998.

The impact of globalisation on strategy. Jean-Marie GuÉHENNo. SURVIVAL. Winter 1998-1999.

Is major war obsolote? Michael MandelbaUm. SURVIVAL. Winter 1998-1999.

La nouvelle oscillation stratégique. Jean DuFourcQ. DEFENSE NATIONALE. Primteps 1999.

De nouvelles exigences stratégiques. Claude Chaufrein. DEFENSE NATIONALE. Primteps 1999.

The Alliance's Strategic Concept. April 1999. NATO OFFICE OF INFORMATION AND PRESS. 1110 BRUSSELS. BELGICA.

Borradores de Trabajo EMACON. 